\title{
Genetic potential for an acute inflammatory response in IgA glomerulonephritis in mice
}

R.S. Kurihara ${ }^{1}$, M. Yokoo ${ }^{1}$, W.V. Domingues ${ }^{1}$, W.H. Cabrera ${ }^{2}$, O.G. Ribeiro², O.M. Ibañez², D.A. Malheiros ${ }^{1}$, R.T. Barros ${ }^{1}$ and E.B. de Almeida Prado ${ }^{1}$

\author{
${ }^{1}$ Laboratório de Fisiopatologia Renal, Faculdade de Medicina, \\ Universidade de São Paulo, São Paulo, SP, Brasil \\ ${ }^{2}$ Laboratório de Imunogenética, Instituto Butantan, São Paulo, SP, Brasil
}

\begin{abstract}
Correspondence
R.S. Kurihara

R. Agostinho Cretella, 58

05337-040 São Paulo, SP

Brasil

Fax: +55-11-3768-3443

E-mail: roshara@uol.com.br

Research supported by CNPq.

Publication supported by FAPESP.

...................

Received October 7, 2004

Accepted June 14, 2005

Accepted June 14,2005 cyte chemoattractant protein-1 (MCP-1) chemokine. IgA nephropathy was induced by intraperitoneal ovalbumin injection and bile duct ligation in AIRmax and AIRmin mice. Histological changes, urinary protein/creatinine ratio, serum IgA levels, immunofluorescence for $\mathrm{IgA}, \mathrm{IgG}$ and complement $\mathrm{C} 3$ fraction, immunohistochemistry for macrophages and MCP-1, and MCP-1 levels in macerated kidney were determined. Mesangial IgA deposition was seen only in AIRmin mice, which presented more renal lesions. Increased serum IgA levels $(1.5 \pm 0.4$ vs $0.3 \pm 0.1 \mathrm{mg} / \mathrm{mL}, \mathrm{P}<0.001)$, high glomerular MCP-1 expression and decreased monocyte/macrophage infiltration in the interstitial area $(0.3 \pm 0.3$ vs $1.1 \pm 0.9$ macrophages/field, $\mathrm{P}<0.05)$ were detected in AIRmin mice compared to AIRmax mice. No glomerular monocyte/macrophage infiltration was detected in either strain. In spite of the absence of $\operatorname{IgA}$ deposition, AIRmax mice presented discrete or absent mesangial proliferation. The study showed that there are differences between mice selected for AIRmax and AIRmin with respect to serum IgA levels, histological damage and MCP-1 chemokine production after ovalbumin injection in combination with bile duct ligation.
\end{abstract}

\begin{abstract}
Mice selected on the basis of an acute inflammatory response (AIR) can provide information about the immunopathological mechanisms of glomerulonephritis. We studied the differences between mice selected for a maximal AIR (AIRmax that attract more polymorphonuclear cells to the site of injury) or a minimal AIR (AIRmin that attract more mononuclear cells) in an experimental model of $\operatorname{IgA}$ nephropathy in order to investigate the effect of genetic background on glomerular disease progression and the participation of the mono-

Key words

- Monocyte chemoattractant protein-1

- $\lg \mathrm{A}$

- Glomerulonephritis

- Acute inflammatory response

- Chemokine
\end{abstract}

\section{Introduction}

Maximal and minimal acute inflammatory response (AIRmax and AIRmin) mice were obtained by bi-directional artificial ge- netic selection for an AIR induced by subcutaneous injection of polyacrylamide beads, a non-antigenic, insoluble and chemically inert substance. The initial population subjected to this selection (named F0) (1) is 
highly polymorphic and was obtained from the interbreeding of eight mouse strains (lineage A, DBA2, P, SWR, CBA, SJL, BALB/ $c$, and C57BL/6).

The phenotype characterizad was the influx of leukocytes and plasma protein into the inflammatory exudate $48 \mathrm{~h}$ after polyacrylamide injection. The mice were selected for the ability to recruit polymorphonuclear cells at the site of injury $(1,2)$. The F0 population presented a predominance of polymorphonuclear cells $(71 \%)$ and $29 \%$ monocytes. In the nineteenth generation (F19), mononuclear cells corresponded to $55 \%$ of the cells in the exudate of AIRmin mice and polymorphonuclear cells corresponded to 95\% of the cells in the exudate of AIRmax mice (2).

Some differences were detected between these two mouse strains. First, the hematopoietic study of bone marrow demonstrated that AIRmin mice produced predominantly more monocyte colony-forming units than AIRmax mice (Ribeiro OG, personal communication). Second, AIRmax mice produced a larger amount of basal serum IgE and prostaglandin E (PGE) in the exudate compared to AIRmin mice (1). Finally, spleen cells from AIRmax mice with chronic arthritis produced a larger amount of IFN- $\gamma(3)$.

In the present study, we determined the differences between mouse strains genetically selected for AIRmax or AIRmin in terms of the development of IgA glomerulonephritis, the influence of monocyte chemoattractant protein-1 (MCP-1), and monocyte/macrophage infiltration. To this end, we used the experimental IgA glomerulonephritis model described by Emancipator et al. (4), modified, with intraperitoneal ovalbumin injections and bile duct ligation in mice, which resulted in mesangial IgA deposits.

Monocytes/macrophages are immune system cells which participate in the transition from acute to chronic glomerular injury (5). These cells are known to be able to secrete products in response to different stimuli such as cytokines, growth factors, lysosomal enzymes, protease inhibitors, fibronectin, cyclooxygenase products, lipoxygenase products, reactive oxygen products, and reactive nitrogen products (6). Macrophages are detected in the presence of both glomerular and non-glomerular injury and are related to the progression of renal disease in the glomerular and interstitial compartment (7). In human $\operatorname{IgA}$ nephropathy there is a correlation between glomerular macrophage infiltration and crescents and proteinuria (8).

One of the most important chemokines involved in monocyte/macrophage attraction to the site of injury is MCP-1 (9). Experimental models using rodents have shown an association between glomerular expression of MCP-1 and monocyte infiltration in these areas $(10,11)$.

\section{Material and Methods}

\section{Animals}

Male and female AIRmax and AIRmin mice aged 6 to 8 weeks, F26 generation, and $\mathrm{BALB} / \mathrm{c}$ mice aged 6 to 8 weeks were obtained from the animal facilities of the Immunogenetics Laboratory, Instituto Butantan, São Paulo, SP, Brazil.

\section{Experiment}

Six animals from the AIRmax and AIRmin groups were used. A solution containing $50 \mu \mathrm{g} / \mathrm{mL}$ ovalbumin (albumin, chicken egg; Sigma, St. Louis, MO, USA), 5 $\mathrm{mg} / \mathrm{mL}$ aluminum hydroxide and $0.9 \%$ sodium chloride was prepared. Mice were immunized with $1 \mathrm{~mL}$ of this solution injected ip once a week for 4 weeks. During the 5th week, the animals were anesthetized with xylazine and chloral hydrate and bile duct ligation was performed. Three days after surgery they were immunized once more and 7 days after surgery they were placed in 
metabolic cages for $4 \mathrm{~h}$ for urine collection. The animals were then sacrificed and blood and kidneys were collected for analysis.

A preliminary study with BALB/c mice was also carried out. The animals were divided into four groups: control $(\mathrm{N}=5)$, mice that did not receive ovalbumin injections and were not submitted to bile duct ligation; ovalbumin $(\mathrm{N}=6)$, mice that received only ovalbumin injections; bile duct ligation $(\mathrm{N}=$ 6 ), mice only submitted to bile duct ligation; ovalbumin and bile duct ligation $(\mathrm{N}=5)$, mice that received ovalbumin injections and bile duct ligation.

\section{Urinary protein/creatinine ratio}

The urine collected for $4 \mathrm{~h}$ was centrifuged and the protein contained in the supernatant was measured by the method of Bradford (12). Next, urine was deproteinated with an equal part of $20 \%$ trichloroacetic acid. Creatinine was determined by the Heinegard-Tiderstrom method, modified, and the result was multiplied by 2 (13). The data obtained were used to calculate the urinary protein/creatinine ratio.

\section{Histology}

One of the kidney poles was first fixed in Bouin solution and then in buffered formalin, and embedded in paraffin. Four-micrometer paraffin sections were stained with hematoxylin-eosin. The other pole was frozen, and frozen 4- $\mu \mathrm{m}$ sections were cut, fixed in acetone for $5 \mathrm{~min}$ and stored at $-70^{\circ} \mathrm{C}$ until use.

Immunofluorescence. The frozen sections were washed with Tris-buffered saline (TBS) for $10 \mathrm{~min}$ and then incubated with primary antibody (1:50 goat anti-mouse IgA; or 1:100 goat anti-mouse $\mathrm{IgG}$, both from Sigma) for $60 \mathrm{~min}$. The sections were washed again with TBS for $10 \mathrm{~min}$ and then incubated with secondary antibody (rabbit anti-goat IgG diluted 1:100; ICN, Aurora, OH, USA) for 30 min. After washing with TBS, the material was incubated with 1:40 FITC anti-rabbit IgG and 1:20 Evans blue for 45 min.

Immunohistochemistry for C3 (complement $C 3$ fraction). Endogenous peroxidase was blocked in the frozen material with $1 \%$ hydrogen peroxide diluted in methanol. The material was washed with TBS and incubated with 1:10 bovine serum albumin for $60 \mathrm{~min}$. The sections were then incubated with 1:200 C3/HRP (ICN) for $30 \mathrm{~min}$ at $37^{\circ} \mathrm{C}$ and left to stand at $4^{\circ} \mathrm{C}$ overnight. The color was developed with diaminobenzidine diluted in TBS and hydrogen peroxide and then counterstained with Mayer's hematoxylin for $8 \mathrm{~min}$ and a semi-quantitative analysis was conducted.

Immunohistochemistry for F4/80 (macrophage staining). Paraffin-embedded sections were used. The immunohistochemical StreptABComplex/AP method (Dako A/S, Glostrup, Denmark), a biotin-streptavidin complex stained with alkaline phosphatase, was adopted. The material was dewaxed,

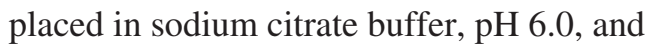
heated $2 \times 8 \mathrm{~min}$ in a microwave oven. Next, the material was washed in distilled water and TBS. Avidin and biotin were blocked for 20 min each and the sections were then incubated with 1:10 fetal calf serum for 60 min. The primary antibody was 1:20 rat antimouse F4/80 (Serotec, Oxford, England) incubated overnight. On the subsequent day, the secondary antibody, 1:300 biotinylated rabbit anti-rat IgG (Dako), was added. After washing, the specimens were incubated with StreptABComplex/AP for $30 \mathrm{~min}$, developed with Fast Red and counterstained with Mayer's hematoxylin. Positive staining/glomerulus and positive staining/field were counted at $400 \mathrm{X}$ magnification.

Immunohistochemistry for MCP-1. Frozen sections and the immunohistochemical StreptABComplex/AP method were used. The primary antibody was 1:50 hamster antimouse MCP-1 (Pharmingen, San Diego, CA, USA) and the secondary antibody was 1:100 goat anti-hamster IgG (Vector, Burlingame, 
CA, USA). A semi-quantitative analysis was carried out.

\section{ELISA for MCP-1}

The right kidney was weighed and macerated in phosphate-buffered saline in a Potter Elvehjem apparatus. The material was centrifuged at $2000 \mathrm{rpm}$ at $4^{\circ} \mathrm{C}$ for $10 \mathrm{~min}$ and the supernatant was stored at $-70^{\circ} \mathrm{C}$. MCP-1 was measured by ELISA using the Quantikine kit, Mouse JE/MCP-1 Immunoassay (R\&D Systems, Minneapolis, MN, USA) and detected with a microplate reader at $450 \mathrm{~nm}$. Sensitivity was $2 \mathrm{pg} / \mathrm{mL}$ and the results were reported as pg/g kidney.

\section{Serum IgA}

Serum IgA levels were determined by radial immunodiffusion (14). Thirty microliters anti-mouse IgA (Sigma) was placed in $1 \%$ agarose and Tris barbital, $\mathrm{pH}$ 8.8. The standard solution was $5 \mu \mathrm{g} / \mu \mathrm{L}$ mouse IgA (Sigma). The samples were diluted 1:2 in Tris barbital and $6 \mu \mathrm{L}$ was added to each well and incubated for $48 \mathrm{~h}$. The material was washed with saline for $72 \mathrm{~h}$, stained with $25 \%$ Coomassie blue, $54.4 \%$ methanol and $13.3 \%$ acetic acid for 5 min, and destained with 5\% acetic acid. The diameter of the halo was measured and concentration was plotted $v s$ diameter ${ }^{2}$.

\section{Statistical analysis}

Data were analyzed statistically by the Mann-Whitney test for nonparametric parameters and by the Student $t$-test for parametric parameters, with the level of significance set at $\mathrm{P}<0.05$.

\section{Results}

\section{Preliminary study in BALB/c mice}

BALB/c mice were divided into four groups: control $(\mathrm{N}=5)$, only ovalbumin injections $(\mathrm{N}=6)$, only bile duct ligation ( $\mathrm{N}$ $=6$ ), and ovalbumin injections with bile duct ligation $(\mathrm{N}=5)$.

There were difficulties in performing the surgery in mice. The mortality after bile duct ligation was $80 \%$ due to surgical procedures and all of these animals were icteric at the time of sacrifice.

Control mice and mice receiving ovalbumin injections did not present any histological changes, but bile duct ligation caused a mesangial expansion in some glomeruli in three of six animals and ovalbumin injections with bile duct ligation increased the intensity of mesangial expansion in three of five animals.

There were no alterations in the interstitial area and no differences in urinary protein/creatinine ratio among the groups (control: $1.4 \pm 0.4$; ovalbumin: $3.9 \pm 0.8$; bile duct ligation: $11.8 \pm 19.9$; ovalbumin with bile duct ligation: $55.1 \pm 108.1$; $\mathrm{P}>0.05$ )

The production of serum IgA antibody was the same for control and for the group submitted to ovalbumin injections with bile duct ligation $(1.6 \pm 0.7$ and $2.1 \pm 0.4 \mathrm{mg} / \mathrm{mL}$, respectively); however, $60 \%$ of control mice had IgA deposition in the glomerular area, as opposed to $100 \%$ deposition in mice with bile duct ligation or ovalbumin injection.

MCP-1 levels were higher in the group submitted to ovalbumin injection and bile duct ligation $(612 \pm 147 \mathrm{pg} / \mathrm{g})$ than in control $(76 \pm 31 \mathrm{pg} / \mathrm{g})$. MCP-1 staining was observed in the mesangial area.

\section{Histology of AIRmin and AIRmax mice}

The following results were obtained for AIRmin mice: no histological alterations ( $\mathrm{N}$ $=1)$, discrete mesangial expansion $(\mathrm{N}=1)$, synechiae $(\mathrm{N}=1)$, mesangial expansion and proliferation $(\mathrm{N}=1)$, and mesangial expansion and synechiae $(\mathrm{N}=2$; Figure $1 \mathrm{C})$.

Three of six AIRmax mice presented discrete mesangial proliferation (Figure 1B).

In one mouse of the AIRmin group we 
observed erythrocytes in tubular space and in 2 mice of AIRmax group, with no histological alteration, we observed erythrocytes in Bowman's space.

No tubulo-interstitial alterations or differences in urinary protein/creatinine ratio (AIRmax: $4.9 \pm 5.6$; AIRmin: $15.4 \pm 22.4$; P $>0.05$ ) were observed between strains.

\section{Serum $\lg \mathrm{A}$ and $\lg \mathrm{A}$, IgG and $\mathrm{C} 3$ deposition in renal tissue}

Serum $\operatorname{IgA}$ antibody production was higher in AIRmin than in AIRmax mice, with $1.5 \pm 0.4 \mathrm{mg} / \mathrm{mL}$ serum in AIRmin mice and $0.3 \pm 0.1 \mathrm{mg} / \mathrm{mL}$ in AIRmax mice $(\mathrm{P}<0.001$; Figure 2D). IgA production was lower in AIRmax than BALB/c mice (2.1 \pm $0.4 \mathrm{mg} / \mathrm{mL}$ ).

$\operatorname{Ig}$ A deposition was observed only in the mesangial region of AIRmin mice (Figure $2 \mathrm{~B})$, with a tendency to IgG deposition in these mice and with no difference in $\mathrm{C} 3$ deposition between AIRmax and AIRmin mice. There was no IgA deposition in AIRmax mice.

\section{MCP-1 and macrophages}

MCP-1 levels determined by ELISA in whole macerated kidney were $1230 \pm 480$ $\mathrm{pg} / \mathrm{g}$ in AIRmin mice and $213 \pm 192 \mathrm{pg} / \mathrm{g}$ in AIRmax mice $(\mathrm{P}<0.01$; Figure $3 \mathrm{C})$. BALB/ $\mathrm{c}$ mice showed an intermediate level of MCP$1(612 \pm 147 \mathrm{pg} / \mathrm{g})$.

Immunohistochemistry was carried out to investigate the MCP-1 production site that showed predominant MCP-1 staining in the mesangial area of AIRmin mice. This chemokine was not detected in AIRmax mice (Figure $3 \mathrm{~A}, \mathrm{~B}$ and $\mathrm{C}$ ).

Macrophages were found in the tubulointerstitial region of AIRmax and AIRmin mice, predominantly in the periglomerular region. No staining for macrophages was observed in the glomerular area of AIRmax or AIRmin mice. AIRmax mice presented
$1.1 \pm 0.9$ macrophages/field and AIRmin mice $0.3 \pm 0.3$ macrophages/field $(\mathrm{P}<0.05)$.

\section{Discussion}

Since we used mice genetically selected for an acute inflammatory response, we expected to induce experimental proliferative glomerulonephritis but we did not succeed in reproducing this model. We induced experimental IgA nephropathy in BALB/c mice

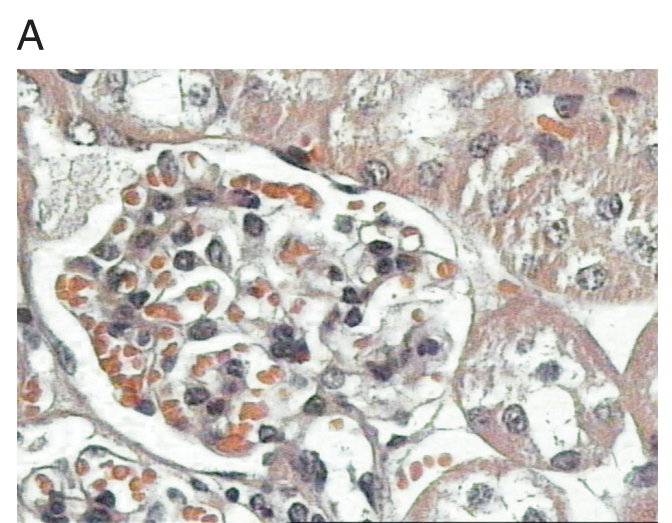

B

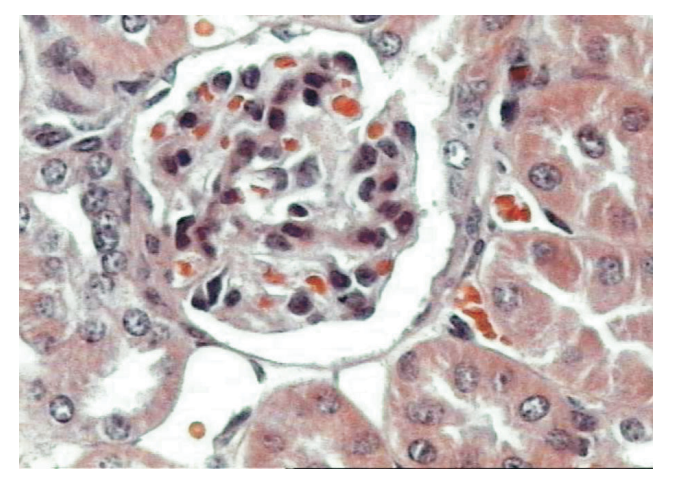

C

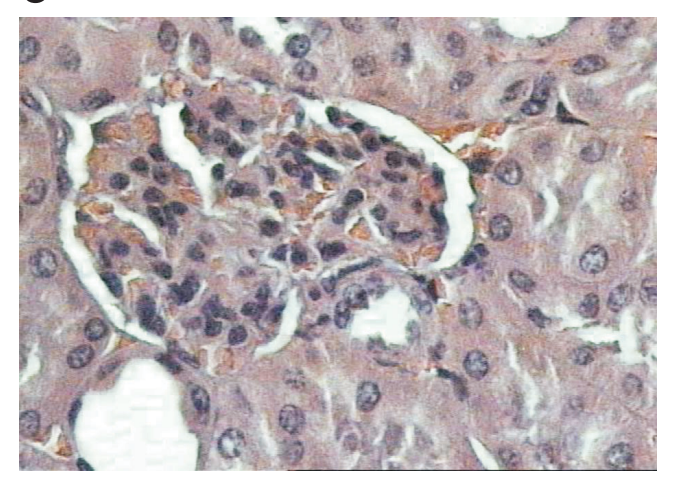

Figure 1. $A$, Glomerulus from a normal maximal acute inflammatory response (AIRmax) mouse. Hematoxylin-eosin (HE), 360X. B, Glomerulus from an AIRmax mouse with mesangial proliferation. HE, 360X. C, Glomerulus from a minimal AIR (AIRmin) mouse with synechiae and mesangial expansion. HE, 360X. 
Figure 2. $A$, Negative staining for IgA by immunofluorescence in maximal acute inflammatory response (AIRmax) mice (360X). $B$, Positive staining for IgA by immunofluorescence in minimal AIR (AIRmin) mice (360X). C, AlRmax and AlRmin mice with bile duct ligation: IgA deposition was increased in AIRmin. $D$, IgA production in AIRmax and AIRmin mice with bile duct ligation: serum IgA levels were higher in AIRmin. Glomerular deposition of IgA in
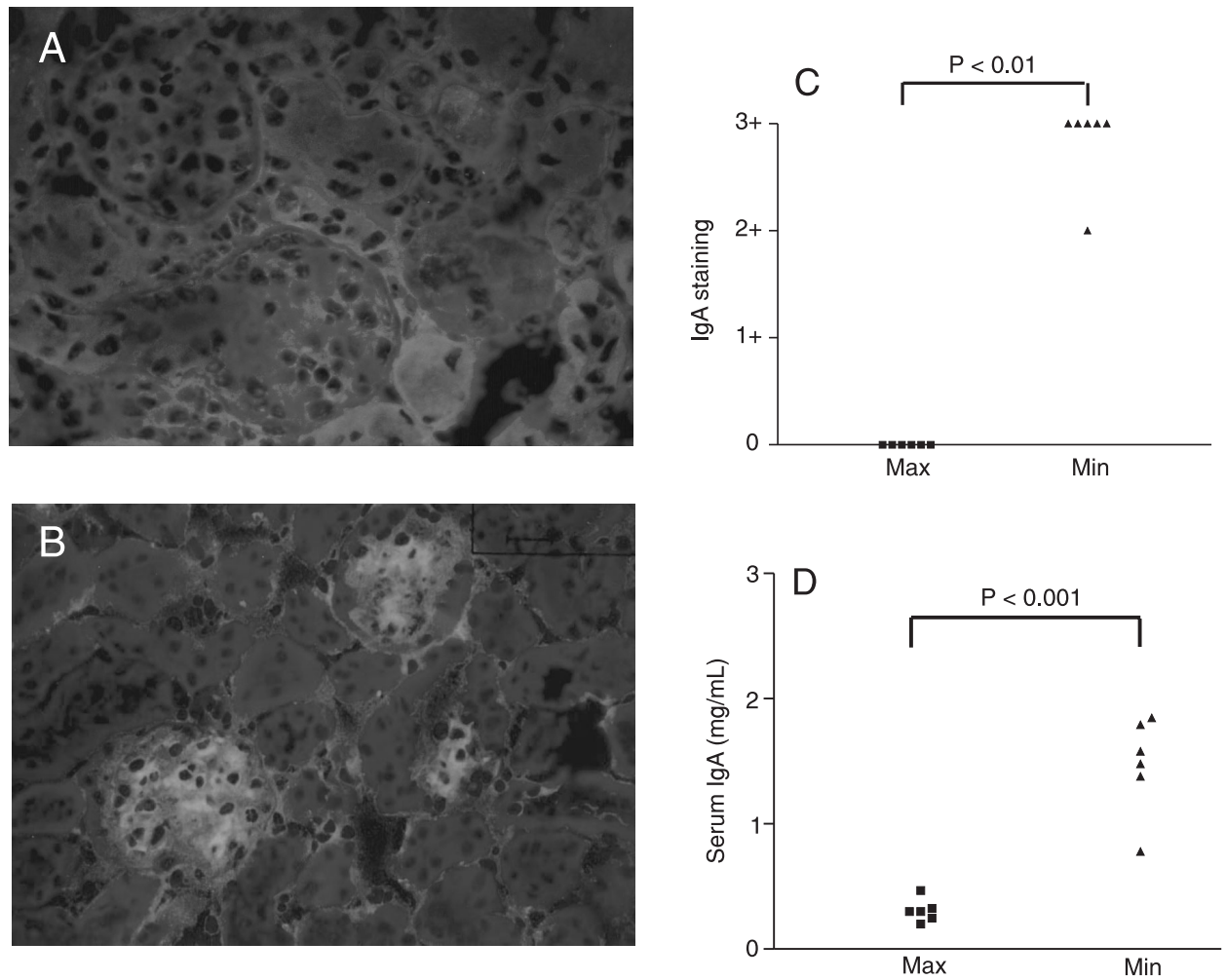

Figure 3. $A$, Negative staining for monocyte chemoattractant protein-1 (MCP-1) in maximal acute inflammatory response (AIRmax) mice (360X). B, Positive staining for MCP-1 in minimal AIR (AIRmin) mice (360X). $C$, MCP-1 levels in macerated kidney from AIRmax and AIRmin mice with bile duct ligation: the levels were higher in AlRmin mice. $D, M C P-1$ intensity by immunohistochemistry in AIRmax and AIRmin mice ( $P>0.05)$.
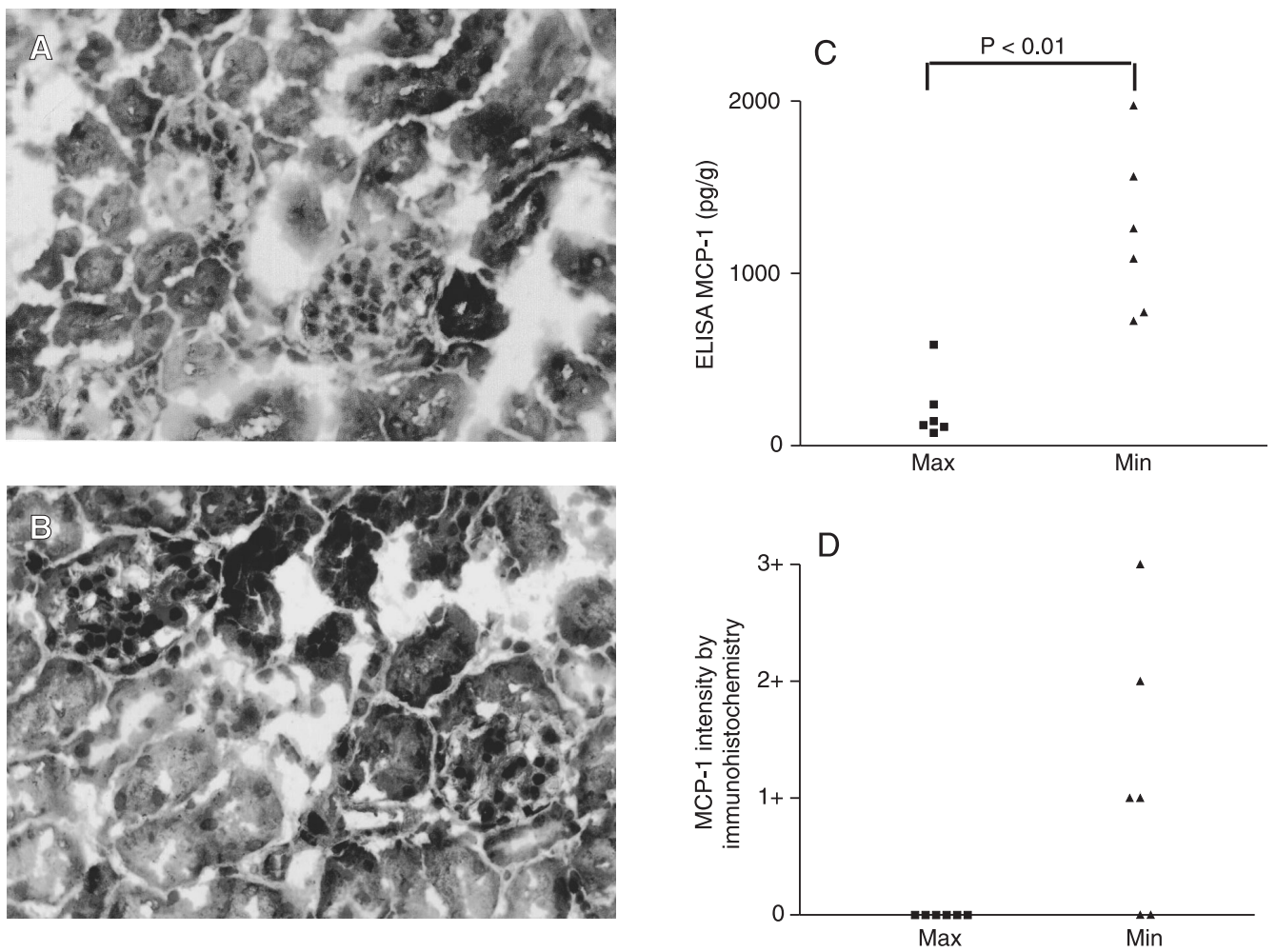
which are an inbred strain of mice, not selected for an acute inflammatory response, and then we applied this model to AIRmax and AIRmin mice to investigate the influence of genetic potential on the acute inflammatory response in the pathogenesis of glomerulonephritis.

The preliminary study in BALB/c mice showed that bile duct ligation with ovalbumin immunization can induce discrete mesangial expansion, in the absence of proteinuria.

The renal alterations were very discrete, probably due to the short time elapsed from bile duct ligation to sacrifice. However, if this interval were increased, other related factors such as surgery or hepatic damage would be more likely to have an effect.

The experiment in mice selected for maximal or minimal genetic acute inflammatory response showed that AIRmin mice presented more histological damage such as mesangial matrix expansion, synechiae and mesangial proliferation. There was IgA deposition in mesangial area and MCP-1 levels were higher in macerated kidney compared to AIRmax and BALB/c mice.

These facts might be related to IgA deposition in the mesangial region but it was observed that AIRmax mice have mesangial proliferation even in the absence of $\operatorname{Ig} \mathrm{A}$ or $\mathrm{IgG}$ deposition in renal tissue. Melvin et al. (15) demonstrated that when bile duct ligation was performed in rats there was an increase in glomerular diameter. This glomerular hypertrophy may cause a stretch in mesangial cells and it is known that exposure to stretch/relaxation stimulates mesangial cell proliferation in vitro (16). In the puromycin aminonucleoside model, the increase in glomerular volume can lead to segmental and focal sclerotic lesions (17).

Nevertheless, there were differences in histological lesions between the two strains. Many studies have associated mesangial proliferation and matrix expansion in both immune and non-immune renal diseases (18-
20). Johnson et al. (21) have demonstrated dissociation between these two phenomena. When IFN- $\gamma$ is administered to rats in the anti-Thy 1 model, mesangial proliferation is partially inhibited and matrix expansion is maintained. In pristane-induced arthritis, IFN- $\gamma$ was increased in AIRmin mice (3), a fact that may explain a tendency to mesangial expansion in this strain.

The reduced serum IgA levels of AIRmax animals may reflect an increase in endogenous regulatory factors in this mouse strain in the presence of surgical stress or bacterial translocation (22). A previous study has shown that intraperitoneal polyacrylamide injection before ovalbumin immunization reduces the anti-ovalbumin response of AIRmax, but not AIRmin, mice. This demonstrates that inflammation before immunization decreases antibody production in AIRmax mice (Araújo LMM, personal communication). Glucocorticoids are known to be increased in stress situations and PGE is increased in the acute inflammatory exudate of AIRmax animals (Ribeiro OG, personal communication), and both could influence immunoglobulin production (23-26).

MCP-1 production was higher in AIRmin mice than in AIRmax mice but AIRmax had a greater macrophage infiltration in the interstitial area. In addition, immunohistochemical analysis showed MCP-1 production in the mesangial area but no macrophages were detected in this region. Some hypotheses have been raised to explain the higher MCP-1 production in AIRmin mice than in AIRmax mice: 1) glomerular IgA deposition stimulating chemokine secretion in AIRmin, 2) MCP-1 production was detected but there was no time to attract macrophages to the site of injury, 3) MCP-1 increased as a reflex of the inability of this mouse strain to protect itself with a sufficient amount of polymorphonuclear cells, needing more monocyte chemoattractants in its constitution, and 4) AIRmax mice have more counter-regulation factors in their con- 
stitution, such as production as glucocorticoids or PGE in response to stress. Dexamethasone inhibits MCP-1 production in fibroblast culture (27) and PGE decreases MCP-1 mRNA expression in anti-thymocyte glomerulonephritis (28). Another factor could be IFN- $\gamma$. This cytokine is increased in AIRmin mice and can stimulate human mesangial cells to produce MCP-1 in vitro, as reported by Grandaliano et al. (29). The dissociation between MCP-1 expression and macrophage infiltration demonstrates that other factors can be involved in macrophage recruitment in this model.

The present study showed the importance of pro-inflammatory genetic modulation interfering with the response pattern in this model, with glomerular IgA deposition causing significant lesions such as synechiae and matrix mesangial expansion in AIRmin mice and the absence of IgA deposition and discrete mesangial proliferation in AIRmax mice.

\section{References}

1. Ibañez OM, Stiffel C, Ribeiro OG et al. (1992). Genetics of nonspecific immunity: I. Bidirectional selective breeding of lines of mice endowed with maximal or minimal inflammatory responsiveness. European Journal of Immunology, 22: 2555-2563.

2. Araújo LMM, Ribeiro OG, Siqueira M et al. (1998). Innate resistance to infection by intracellular bacterial pathogens differs in mice selected for maximal or minimal acute inflammatory response. European Journal of Immunology, 28: 2913-2920.

3. Vigar ND, Cabrera WHK, Araújo LMM et al. (2000). Pristane-induced arthritis in mice selected for maximal or minimal acute inflammatory reaction. European Journal of Immunology, 30: 431-437.

4. Emancipator SN, Gallo GR, Razaboni R et al. (1983). Experimental cholestasis promotes the deposition of glomerular IgA immune complexes. American Journal of Pathology, 113: 19-26.

5. Schreiner GF (1991). The role of the macrophage in glomerular injury. Seminars in Nephrology, 11: 268-275.

6. Nathan CF (1987). Secretory products of macrophages. Journal of Clinical Investigation, 79: 319-326.

7. van Goor H, Ding G, Kees-Folts D et al. (1994). Biology of disease: macrophages and renal disease. Laboratory Investigation, 71: 456464.

8. Arima S, Nakayama M, Naito M et al. (1991). Significance of mononuclear phagocytes in IgA nephropathy. Kidney International, 39: 684-692.

9. Rollins BJ, Walz A \& Baggiolini M (1991). Recombinant human MCP-1/JE induces chemotaxis, calcium influx, and the respiratory burst in human monocytes. Blood, 78: 1112-1116.

10. Rovin BH, Rumancik M, Tan L et al. (1994). Glomerular expression of monocyte chemoattractant protein-1 in experimental and human glomerulonephritis. Laboratory Investigation, 71: 536-542.

11. Tam FWK, Karkar AM, Smith J et al. (1996). Differential expression of macrophage inflammatory protein 2 and monocyte chemoattractant protein-1 in experimental glomerulonephritis. Kidney International, 49: 715-721.

12. Bradford MM (1976). A rapid and sensitive method for the quantitation of microgram quantities of protein utilizing the principle of protein-dye binding. Analytical Biochemistry, 72: 248-254.

13. Lopes HJJ, Sousa MO, Ratton VLA et al. (1989). New formulation for the preparation of the alkaline buffer used in the determination of blood's and urine's creatinine - modified Heinegard-Tiderstrom's method. Revista Brasileira de Análises Clínicas, 21: 121-125.

14. Mancini G, Carbonera AO \& Heremans JF (1965). Immunochemical quantitation of antigens by single radial immunodiffusion. Immunochemistry, 2: 235-254.

15. Melvin T, Burke B, Michael AF et al. (1983). Experimental IgA nephropathy in bile duct ligated rats. Clinical Immunology and Immunopathology, 27: 369-377.

16. Harris RC, Akai Y, Yasuda T et al. (1994). The role of physical forces in alterations of mesangial cell function. Kidney International, 45 (Suppl): S17-S21.

17. Cahill MM, Ryan GB \& Bertram JF (1996). Biphasic glomerular hypertrophy in rats administered puromycin aminonucleoside. Kidney International, 50: 768-775.

18. Johnson RJ, Raines EW, Floege J et al. (1992). Inhibition of mesangial cell proliferation and matrix expansion in glomerulonephritis in the rat by antibody to platelet-derived growth factor. Journal of Experimental Medicine, 175: 1413-1416.

19. Floege J, Eng E, Young BA et al. (1993). Heparin suppresses mesangial cell proliferation and matrix expansion in experimental mesangioproliferative glomerulonephritis. Kidney International, 43: 369-380.

20. Fukui M, Nakamura T, Ebihara I et al. (1993). Low protein diet attenuates increased gene expression of platelet-derived growth factor and transforming growth factor-beta in experimental glomerular sclerosis. Journal of Laboratory and Clinical Medicine, 121: 224234.

21. Johnson RJ, Lombardi D, Eng E et al. (1995). Modulation of experimental mesangial proliferative nephritis by interferon- $\gamma$. Kidney International, 47: 62-69.

22. Deitch EA, Sittig K, Li M et al. (1990). Obstructive jaundice promotes bacterial translocation from the gut. American Journal of Surgery, 159: 79-84.

23. del Rey A, Besedowsky H \& Sorkin E (1984). Endogenous blood levels of corticosterone control the immunologic cell mass and $B$ cell activity in mice. Journal of Immunology, 133: 572-575.

24. McLeish KR, Gohara AF \& Gunning WT (1982). Suppression of antibody synthesis by prostaglandin $\mathrm{E}$ as a mechanism for preventing murine immune complex glomerulonephritis. Laboratory Investi- 
gation, 47: 147-152.

25. Kelley VE, Winkelstein A \& Izui S (1979). Effect of prostaglandin E on immune complex nephritis in NZB/W mice. Laboratory Investigation, 41: 531-537.

26. Zurier RB, Damjanov I, Sayadoff DM et al. (1977). Prostaglandin E1 treatment of NZB/NZW F1 hybrid mice. II. Prevention of glomerulonephritis. Arthritis and Rheumatism, 20: 1449-1456.

27. Mukaida N, Zachariae CCO, Gusella GL et al. (1991). Dexamethasone inhibits the induction of monocyte chemotactic-activating factor production by interleukin-1 or tumor necrosis factor. Journal of
Immunology, 146: 1212-1215.

28. Jocks T, Zahner G, Freudenberg J et al. (1996). Prostaglandin E1 reduces the glomerular mRNA expression of monocyte chemoattractant protein-1 in anti-thymocyte antibody-induced glomerular injury. Journal of the American Society of Nephrology, 7: 897-905.

29. Grandaliano G, Valente AJ, Rozek MM et al. (1994). Gamma interferon stimulates monocyte chemoattractant protein-1 in human mesangial cells. Journal of Laboratory and Clinical Medicine, 123: 282 289. 